\title{
Gender Construction and Divorced Women in Morocco: Fez City as a Case Study
}

\section{Soukayna $A^{*}$}

University of Debrecen, Hungary

\begin{abstract}
This dissertation examines the status of divorced women in Moroccan society, Fes in particular. It is based on the hypothesis which claims that divorced women occupy a third space; neither equal to men nor to other women. This research seeks to fill in the gaps that are found in some works by sociologists that tackled the issue of divorced women in Morocco and attempts to investigate this issue from a different angle. The dissertation tries to analyze the position of divorced women in Moroccan society through the lenses of people from different ages and backgrounds. The viewpoints of people are obtained through the two effective data collection instruments, questionnaire and interview. The study is conducted in Fes and the sample adopted acts as an added value to the findings. Educated and non-educated people as sampler in forces the importance of the topic and the credibility of the data been elicited for the purpose of reaching valid results.
\end{abstract}

Keywords: Status; Social; Divorced women; Third space; Humanity; Gender

\section{Introduction}

Moroccan women raised in a traditional environment are unable to seek divorce under any circumstance. In the past when traditional values used to prevail, women had not the courage to ask for divorce and break the norms that they grew up with. They used to avoid divorce since they are committed to perform the role of the wife and the mother. Also, Islam has clearly stated that the most abominable thing to God is divorce; the hadith prevents women from resorting to divorce as a first solution and thus women avoid divorce by following instruction of Islam. Furthermore, the fact that Morocco has always been a patriarchal society par excellence, women have always been confined to certain roles which define who a typical Moroccan woman is. She is mainly a wife who does all household shores and raises 'her' children to guarantee the prosperity and the welfare of the family. These roles are often ascribed to women from an early age as a preparation for marriage.

Divorce in Morocco is a phenomenon that is widely spread among all the social classes. Mustapha Ramid, the minister of justice, declared that divorce has reached 40.850 in 2013 against 7.213 cases in 2004 [1]. This number reveals the rapidity by which the rate of divorce augments. The increase of divorce rate might be attributed to many changes that happen in society among them, women's participation in the work market, rebel against the shackles of tradition, emancipation through education and technology and Mudawana that has granted women more rights. All these factors have contributed, in a way or another, in the number of women who are either abandoned or divorced. Since any patriarchal society-Moroccan society included- does not allow any kind of development or improvement to women and puts a ceiling glass that stands against change and achievements, women will feel certain imprisonment either bachelors, married or divorced. However, if divorce is increasing, as above-mentioned, it is because women have felt the need to get emancipated, venture and risk their safety sometimes for the sake of realizing this relative freedom.

The worlds of man and woman are relatively different. Yet, The male world and the female world overlap only in case of marriage, that is a life contract in which both women and men reckon that they are obliged to tune their behaviour according to certain sets of norms that feature marriage and strive as not to deviate or misbehave. Marriage occurs within this conventional social framework; both contractors are submitted to all social norms and their marriage is acknowledged as legitimate when it accomplishes all the institutional requirements. Moreover, the couple is expected to endorse and reinforce the prevailing traditions and adhere consciously or unconsciously, willingly or unwillingly to society. No matter the difference between the world of man and the world of woman is, both of them have to abide by the values and the conceptions of society. In fact, the whole society blesses normative marriage which is regulated by certain standards but curses any other kind of connection which takes place out of the widely accepted social platform.

Within this context, the present paper investigates the status that divorced women occupy in Morocco, Fes in particular. It departs from the hypothesis that divorced women are more likely to occupy a "third space" in Moroccan society, neither equal to men nor to other women. Thus, the study aims at exploring the position of divorced women inside the Moroccan society through gathering opinions of English students from the faculty of letters Dhar el Mehraz and common people from Fes. The distribution of questionnaires besides conducting interviews are means that help in the variation of information and the enrichment of the results. Furthermore, the study necessitates a profound analysis of the status that Moroccan society and culture assigned for divorced women. Also, it is necessary to figure out the extent to which modernization and the new values have succeeded in enacting social change Morocco, specifically in Fes.

For the purpose of exploring the status of divorced women in Morocco, Fes in particular, certain questions are adopted to guide the whole research paper. The study necessitates three research questions.

*Corresponding author: Soukayna A, PhD Candidate, University of Debrecen, Hungary, Tel: +3652258058; E-mail: Soukaynaalami@outlook.fr

Received August 12, 2018; Accepted September 20, 2018; Published September 26, 2018

Citation: Soukayna A (2018) Gender Construction and Divorced Women in Morocco: Fez City as a Case Study. Arts Social Sci J 9: 409. doi: 10.4172/21516200.1000409

Copyright: (c) 2018 Soukayna A. This is an open-access article distributed under the terms of the Creative Commons Attribution License, which permits unrestricted use, distribution, and reproduction in any medium, provided the original author and source are credited. 
Firstly, what are some of the factors that would contribute to the construction of the "third-space" for divorced women in Morocco? Secondly, how this third-space is constructed? Finally, does culture contribute in the stigmatization of divorced women through labeling them in a "third space"? The three provided questions are created to determine the factors that lead to the construction of the status that divorced women occupy in Morocco. In addition, the study attempts to comprehend the mechanisms that are used to create the third space for divorced women, including the role of culture in their stigmatization.

Gender construction affects all human spheres and no human being seems able to escape this cultural necessary condition. If gender is socially constructed, then divorcée as a social status is culturally constructed as well. Zimmerman, an American professor and sociologist at the University of California, Santa Barbara, asserts that "it is individuals who do gender" [1], that is to say, individuals are the agents of sex differences and the ones who give legitimacy to the categorization of babies as feminine or masculine inside a given society. He goes further by defining 'doing gender' as creating differences between girls and boys, men and women, differences that are not natural, essential, or biological.

People contribute in a huge way in the construction of their children's gender. From an early age, these children observe gender as a role that direct their lives and guide it to one sex category, either male or female. Moreover, Zimmerman claims that when parents start labeling the sex of their children by calling them either a boy or a girl, these latter begin to realize their identity and understand that the use of sex categorization in interaction is obligatory [2]. For instance, when the parents tell their little boy "you should be strong, you are a boy", they automatically inculcate in their child's mind that he should be identified with boys and later with men.

Subsequently, due to the social construction of gender, both males and females commence to behave on the basis of their specific sex. First, girls begin to play with toys that are more likely to be feminine like dolls and boys play with masculine ones like trucks. Second, they act according to the values and principles they acquired and constructed from their parents and the society they live in. Anthony Schullo, a public speaker in Ted, discusses gender construction from different angles, mainly the angle of parents and schools. He argues that parents choose toys, actions and clothes for their children according to their gender and they use gender to construct the reality of their children [3]. The construction of gender is all about communicating messages and symbols about how to be a man or a woman; what children should be and should do, instead of what they can be or can do.

Furthermore, Simone de Beauvoir, French philosopher and one of the pioneers of feminist theory, criticizes this issue by giving examples of parents who teach their children, specifically women, manners such as how to sit, how to walk, how to talk and so on. These manners acquired during childhood affect their daily life in general and their marital life in particular, in the sense that girls become rigid, shy and sensitive vis-à-vis others. Second, the process of boys' socialization is characterized by specific toys and a tough sort of education. Boys start acting violently towards their peers, unlike girls who tend to be more quite as it is mentioned earlier. Therefore, the process of gender construction for both boys and girls is more likely to start even before the birth of either boys or girls.

The process of gender construction begins even before the birth of the child. The parents usually choose color of clothes, toys, and everything that would suit the sex of the baby; pink for girls and blue for boys. This point is highlighted through an article entitled "The Social Construction of Gender" by Margaret L. Andersen, a professor at University of California Berkeley, which revolves around the idea of parents who might buy gifts to their children with images and symbols that promote certain stereotypes depending on the expected sex of the unborn child. Once the baby is born, the room is decorated with stuff that reveals to everyone the sex of the baby and most importantly the sticker which tells "it's a boy" or "it's a girl".

\section{Part One: Theoretical Perspectives: Gender Construction and Third Space}

\section{Gender construction: masculinity vs. femininity}

Gender roles: Femininity and masculinity are enacted in society to be taken as gender roles. These latter are roles that are supposed to be performed by men and women within the norms that are set by society. The belief that a behavior of a person determines his/her gender prevails in cultures that encourage stereotypes in gender roles. For example, women are thought to be "naturally" caring and loving and men are breadwinners and resilient; therefore, their women's role must be taking care of the husband and children and men should protect the family and cater for it. Furthermore, the cultural expectations constitute the gender role of a person based on his/ her sex and this person has to conform and play the role so as to confirm the expectations.

Gender roles are tackled from different perspectives according to various disciplines. Amy Blackstone (2003), a professor and researcher in the field of sociology, introduced four major perspectives from which gender roles could be explained. First, the ecological perspective suggests that gender roles are produced by the interaction between individuals themselves who contribute in the construction of gender roles and between their communities and environments. Second, the biological perspective claims that women are naturally attached to more feminine gender roles, whereas men are naturally affiliated to masculine roles. Third, the sociological perspective believes that gender roles are learned and that masculine and feminine roles are not necessarily related to the biological characteristics of males and females. Fourth, the feminist perspective suggests that there is inequality as far as gender roles are concerned; that is to say, in gender roles, men hold powerful positions in society since they are expected to be protectors and breadwinners of the family unlike women who are less likely to be in good status, especially after divorce [4].

Blackstone goes further by claiming that gender roles are not only limited in the private sphere like home and family but also in the public sphere like work [5]. Men and women are expected to occupy different jobs based on many criteria such as physical conditions, intelligence and experience. Traditional gender roles are the determining factor behind the different jobs and tasks that are given to any person based on his or her sex. Traditional gender roles limit the possibility of change and promote patriarchy; in other words, women are expected to work as assistants, nurses and secretaries; whereas men are more likely to occupy roles that are prestigious such as managers and decision makers. In addition, gender roles engender gender gap; in traditional cultures, women are usually less paid than men and this decision is based on stereotypes that give privilege to men since they are the providers of the family and underestimate women because their role is limited within nurturing. For instance, in traditional societies parental leave is given only to women, whereas it should be given to both husband and wife, as if it is women's responsibility alone to take care of the newborn baby. This can be attributed to gender stereotypes 
that promote women's role as mothers and child bearers and overlook the responsibility of the man as a father.

Gender roles are strengthened by gender stereotypes in the sense that individuals base their perceptions regarding gender roles on gender stereotypes. Gender stereotypes "tend to include exaggerated or erroneous assertions about the nature of males and females". For instance, the common conception of people about the nature of males is that they are tough and rigid whilst women are typically stereotyped of being sensitive, curious and irrational. This kind of role classification based on sex and gender stereotypes does not preserve traditional values or morals, but rather widens the gap of inequality between men and women and offers a space for slow social change.

In more modern societies, gender roles are dissolving and taking new dimensions. Gender roles in some countries are changing because individuals are getting more and more aware of gender issues. In modern societies, there are stay at home fathers that do all household chores related to house; they wash the dishes, look after their children, prepare food, etc and women go out to work in order to earn money and provide for the family. Stay at home dads and working mothers is even increasing through time. According to U.S. Bureau of Consus, in 1975, 47 percent of women with children under 18 worked outside the home. In 2009, 71 percent of women with children under 18 work outside the home [6]. These statistics show the extent to which social change prevails in western societies and enhances gender equality. The social change that is achieved through dissolving gender roles in modern society gives a dimension of progress and development as far as gender roles are concerned. Thus, gender roles need to be redefined because they are neither static nor everlasting; they can be changed through time and by awareness. All that is needed is a first step and a good initiative to progress in life.

\section{The construction of "third space"}

Introducing the concept of "third space": The "third space" is a concept that is attributed mainly to Homi Bhabha, one of the most significant theorists in post-colonial studies. It has been widely borrowed and used by other scholars, either in postcolonial studies or cultures studies in general, to account for in-betweeness. It refers mainly to a constructed space that appears from the meeting of two cultures of different values and characteristics as whole. The result in this sense emerges on a hybrid product that inherits aspects from the two forces and forms, hence a new identity and cultural product. Another use of this notion of third space is found in the works of Franz Fanon or Chinua Achebe to account for another different postcolonial phenomenon. During the encounter of the colonized and the colonizer, the antagonism creates certain in impact on both sides, especially on the part of the colonized. This latter, the vulnerable in this type of meeting, in an attempt to imitate his superior adopts certain behavioral patterns aiming at attaining the same status as the colonizer. This attempt sentence the colonized to experience certain feeling of anxiety and results in an status of neither the same as before nor the one as wished for, a condition of in-betweeness that torments the colonized for the whole of his existence.

[The third space] is an 'interruptive, interrogative, and enunciative' space of new forms of cultural meaning and production blurring the limitations of existing boundaries and calling into question established categorizations of culture and identity. According to Bhabha, this hybrid third space is an ambivalent site where cultural meaning and representation have no 'primordial unity or fixity' [7].
This quote emphasizes the fact that the third space cannot be easily explained but rather a complex concept that calls for more interrogation. It is ambivalent and blurs the meaning of fixity in the sense that the limits or the boundaries are no more visible. According to Bhabha, identity does not remain as it was before or as it is in the boundaries of this third space. This latter creates confusion and ambivalence caused by interruptions and interrogations of the fixed norms.

As mentioned earlier, in particular the second meaning, third space best describes the state of the colonized that is no longer at ease; that is to say, he is neither himself nor can he become what the colonizer urges him to be. Occupying a position between two poles is characterized by stigmatization and anxiety and trauma. The person in this position of third space usually does not feel at ease and is filled with eager towards ill-defined aims. It is a condition of stress and depression in which the person is condemned to endure a schizophrenic split of his ego and alienation. Such unhealthy social existence does not affect, unfortunately, the colonized only; rather its symptoms are to be diagnosed all over the world.

The paper addresses one of the manifestations of this cultural phenomenon that lies among divorced women in Moroccan society whose condition resembles to a large extent that of the colonized. The female body, as certain scholars contend, might be the favorable space upon which patriarchy is exerted its power and inscribes its decrees and rules. Leila Abouzeid, assimilates this patriarchal interventions on the female body as that exercised by a powerful country when it colonizes another weak one. In this respect, the latter is weakened and striped of its natural order of existence and made docile and submissive living in a state of alienation. Hence, to regain its rehabilitation, decolonization remains the sole ultimate option. Thus for the female body to reassert its essence and affirm its existence, any patriarchal shackles should be toppled down so as to leave room to the proper feminine existence to flourish in its own territory.

Divorced women are neither married nor single; their status in society is divorcee or divorced. The word divorce itself shows the extent to which the status of a divorced woman in society is low and inferior. According to the Oxford dictionary, divorce is "the legal dissolution of a marriage by a court or other competent body". There are many definitions to divorce but this definition is more accurate to the topic of this research paper because it gives a clear understanding of the word divorce which means annulment or dissolution of a legitimate contract between a man and a woman [8]. A divorced woman is a person divorced from society and from the ordinary life of a married woman. She is in a state of in-betweeness-that is to say, she is neither free to live her life like a single girl nor married with a stable home.

Divorced women are discarded and looked down by women themselves and individuals. Some women might sympathize with divorced women since they believe that they are all alike in society and they undergo more or less the same circumstances. Others, however, think that divorced women deserve the situation they are in because they did not manage to preserve their house and their family; they are doomed to suffer. On the one hand, there are women who support society in stigmatizing divorced women because they see that those women fail to perform their role as housewives in terms of doing household chores and satisfying the husband or as mothers in the sense of taking care of their children. Moreover, in book Naamane Guessous, a Moroccan sociologist, asserts that some women would not permit a divorced woman to occupy the same status as a girl or a wife because according to society every status has its own characteristics that should not be changed or twisted anyhow [9]. In one of her articles which 
tackle women and society issues, Lamrabet confirms the idea that the enemy of a woman is a woman. She adds that if you ask some women, they might say that a divorced woman gets the state of divorced because she is the kind of women who like to go out constantly and have fun with friends neglecting her house and her children [10]; whereas men, by nature, want women who would take care of them and serve them when they come tired from work. That's why divorced women are looked down by individuals and sometimes by women as well.

On the other hand, traditional society always put the blame on divorced women for being unable to act the way they are taught since they were children. Their mothers and grandmothers raise them on particular values and principles mainly respecting traditions and norms. At that time, marriage was the most important thing that a female should be prepared to. A female should know how to be a good wife and a good mother and all this should be among the frame of tradition and customs. These latter controls the whole scheme of marital life, that is to say, the wife has to be submissive and faithful to her husband; she has to manage her house and look after her children, if she has any. To put it in other words, the values and norms that she has been socialized for need to be applied in her marital life. Therefore, when a woman does not succeed to fit in the mold that society wants to put her in and fails to maintain her marriage, she has to pay the price. This latter would be stigmatization and an in-betweeness position. "Women were likewise made aware of the consequences of any type of transgression of the rights and obligations given or forced on them"

A divorced woman is restricted within the category of inbetweeness. She is neither like other married women nor like men. "She is a bachelor but no more a virgin". Guessous, a Moroccan sociologist, points out the position of divorced women in society in her book Bla Hchouma. She contends that "the woman finds herself, without a husband, in an unaccepted situation in the viewpoint of society; she is single and no more a virgin but with no husband." (author translation). First, married women are seen by individuals and society as real wives with home and family. Lamrabet criticizes the situation of divorced women and their reality in the Moroccan society. She argues that divorced women are in a position which allows them to go out alone without having to hear rumors and gossips and without having to deal with pointed fingers [11]. Moreover, they are labeled within the category of wives and probably mothers; all this is gathered within the grouping of femininity. Second, men are more likely to have a powerful status in society while married and divorced women are less likely to have such authority. They enjoy more freedom, they are not much judged and they belong to the segment of masculinity whatsoever their marital status or their position in society is. Third, divorced women are limited within the category of 'third space', an in-between position which is neither feminine nor masculine. They are in a situation of confusion and torment. Besides this, society excludes them from the category of femininity and puts them in a dark space because they do not manage to keep the characteristics of femininity, but instead they trespass the limits and break the rules and norms of femininity. The third space that society puts divorced women in engenders stereotypes about them. In other words, the third space makes divorced women seem immoral and lustful because they have no man to protect them and no marital house to stay in.

Moreover, society creates a zone for divorced women to keep them excluded from the common life till they find another man with whom they would construct another marital life. "Divorced women become vulnerable group of people who lacks support; emotionally, socially, and financially and suffers loss of their freedom and dignity (they subject to the authority of their fathers, mothers, and brothers)". The loss of freedom, dignity and so on that divorced women suffer from could vanish only when the woman accepts to be under the protection of another man. This point is tackled by Lamrabet who suggests that the possible solution that a divorced woman could have to get rid of that third space is to remarry another man and become under his protection [12]. Hence, society would reintegrate a divorced woman in the category of femininity only if she goes back to the 'right' path, which is marriage and traditional norms that society has made to every female.

In addition to this, society has made the construction of the third space its major aim. As society constructs gender, it has also constructed 'the third space'. Society made it clear that whoever violates the norms is doomed to suffer by constructing the third space as a kind of punishment to disobedience. This means that divorced women are imprisoned within this category to make them understand that there is no way of being feminine other than having a husband and performing the roles that are appropriate for each sex. Additionally, the social construction of the third space is done through the process of self-torture such as psychological trauma (will be dealt in the subtitle) and stigmatization by the family, people and society as a whole. This process is deliberately done to confirm that marriage enhances femininity and makes women follow the correct track.

\section{Part Two: The Status of Divorced Women in Morocco: Fez as a Case Study}

\section{Data analysis}

The research paper discusses the position in which divorced women live in Morocco, Fes in particular. The study is based on the hypothesis which claims that divorced women in Morocco are more likely to occupy a "third-space" or to be in-between. This position might be seen as the consequence of the categorization to which divorced women are subjected. A divorced woman is neglected by society and observed by most people as a stigma which can only exist in an in-between position; that is to say, neither equal to women nor to men. Hence, the study aims at investigating closely this claim, and verifying whether or not divorced women truly occupy a 'third space' in Morocco.

The study is conducted in Fez city for the reason that the population is accessible as there are no constraints that could hinder the process of research. The sample population chosen in this study is students (females and males) from the English department of University Sidi Mohamed Ben Abdellah Dhar El Mehraz-Fes and common people that would represent the inhabitants of Fes city. Moreover, this population is chosen because it is important to know the viewpoints of all the categories of people in order to see the extent to which the issue is feasible in reality; that is to say, to deeply approach whether people believe that divorced women occupy a third space or not. In addition to this, the choice of the population will enable us to figure out whether there is a change in Moroccan society concerning how people perceive divorced women or traditional misconceptions are still controlling the Moroccan society.

This study relies on random sampling as a technique in order to choose a representative sample of students' and people's point of view. This technique is used since it is considered the most objective tool. Adopting this technique, the study gives people, regardless of their gender, social background and age, the chance to participate in this study and share their beliefs as well as their views, instead of having divorced women alone as sample of population, given the fact that it is 
hard to find and address divorced women so as to question them and elicit the data needed for the study.

Since the nature of the topic will not allow access to a large sample population and the constraints related to the approachability of divorced women, the study will make use of the qualitative approach. Both quantitative and qualitative approaches will be adopted however. On the one hand, the quantitative will be helpful in determining the profiles of people who tend to be biased towards divorced women. Besides, relying on five-likert scale, the questionnaire will reveal the attitudes of people vis-à-vis divorced women. It will also measure the factors that contribute to sentencing divorced women to such dark space and how this situation influences them. On the other hand, the qualitative approach will be efficient in giving in-depth explanations about attitudes of Moroccan people towards divorced women and the reasons as well as the impacts of the third space that divorced women are restricted in. Mixing both approaches will increase the validity of the data, enable the researcher to cross check the findings and ensure the reliability and credibility of data, and therefore the quality of the findings.

The first data collection instrument to be used in this study is the questionnaire. A questionnaire is a quantitative data collection procedure that is used to measure the quantity, amount and the frequency of something. One of the strengths of the questionnaire in this study, is to collect quantitative data related to the profiles of people who tend to be biased towards divorced women and those who perceive them negatively. Since one of the weaknesses of the questionnaire is its limitation with respect to eliciting in-depth answers from the respondents, interviews will also be used to collect data. This qualitative data collection procedure is used to give the respondents time and scope to express their opinions about a particular subject, and it allows the researcher to elicit in-depth information around the topic. One of the strengths of the interview in this study, is the fact that it will help in finding out the attitudes of educated and non-educated people regarding the restriction of divorced women in a third space in Morocco society and drawing comparisons between different respondents' experiences and answers.

The data analyzed in this section is collected through questionnaires and interviews. The number of questionnaires distributed to students and common people is two hundred; however, only one hundred and sixty one questionnaires are handed back. The questionnaires are written in English and Arabic versions. The English version is distributed to English students in the Faculty of Letters and Human Sciences, Dhar El Mehraz, Fes and the Arabic version is given to common people in Fez. English students are chosen to represent the elite; the category of educated people that probably have modern views about divorced women and Moroccan society, whereas common people represent the population of fez which is various. People of different ages and have different stances. In addition to questionnaires, twelve people are interviewed for further information and elaboration that could not possibly be gathered from the questionnaire. The interviews are done with random respondents; English students are asked in English whilst common people are interviewed in Moroccan Arabic. Thus, this mixture is helpful in testing the hypothesis so that the study does not rely only on university students and the results would not be biased.

The results accumulated from one hundred and sixty one questionnaires yielded that the number of males and females in this study is variant; that is to say, there are 79 male and 82 female respondents. Thus, $49.1 \%$ represent males and $50.9 \%$ stand for females as Figure 1 illustrates. These results are the outcome of a random distribution of

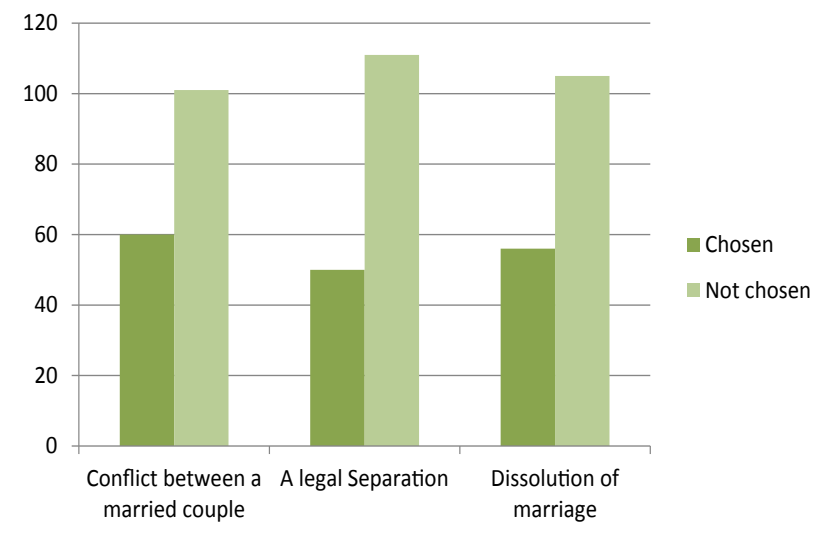

Figure 1: Expressions that describe 'Divorce'.

questionnaires to both sexes, that is to say, the questionnaires were not distributed to $50 \%$ of females and $50 \%$ of males. Consequently, it was not meant to choose female respondents over male respondents in the distribution of questionnaires.

\section{The image of divorced women in fez}

The Perception of divorce among the population of fez: The respondents are given three choices that describe the word divorce to choose from. In their responses, participants favored two major expressions that are more likely to describe the word 'divorce': 'conflict between a married couple' and 'dissolution of marriage' as Figure 2 shows.

According to the results, $37.3 \%$ of respondents opted for 'conflict between a married couple' as a description to divorce. This choice might be chosen for the fact that before any separation between a married couple, there are reasons which contribute to the decision of divorce mainly conflicts or problems that happen between couples and engender break up. In addition to that, $34.8 \%$ of respondents chose 'dissolution of marriage' as a way to describe 'divorce'. This can be explained by the fact that when divorce takes place, the marital life comes to its end and that lifelong contract does not exist anymore. However, 'a legal separation' as a definition of divorce is adopted by $31.1 \%$ of respondents. This is probably due to the simplicity and the common use of 'legal separation' by people as a quite straightforward definition of divorce. There are other suggestions of 'divorce' that are suggested by the respondents such as unsolved problems between the husband and his wife, unsuccessful marriage, lack of communication and the last solution between a married couple.

Concerning the expressions that describe divorced women, the results yielded that there are four major terms: victimized, oppressed, stigmatized and irresponsible as the Figure below illustrates.

A close analysis of Figure 2 demonstrates that the majority of respondents with a percentage of $41.6 \%$ opted for 'victims' as a way to describe divorced women. This choice can be explained by the fact that people believe that divorced women in Morocco are victimized. They are victims of the patriarchal society and the gossips of people. As it is mentioned in the theoretical part, divorced women are always the ones in charge of divorce; the blame is often put on them whereas most of the times divorced women are the victims of domestic violence, marital rape and so on. Therefore, Morocco, as a patriarchal society, often accuses women of being responsible of every problem that occur in marriage and lead to divorce. The woman has always to maintain a 


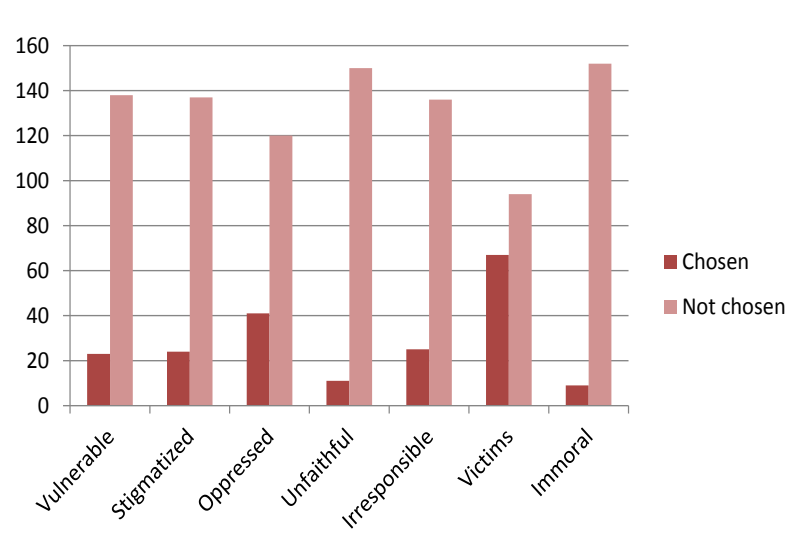

Figure 2: Terms that describe the situation of divorced women.

healthy relationship; the Moroccan culture entails that a woman's duty is to preserve her marital house, to please her husband and save her marriage at any cost. Thus, even if the woman is the victim, she has to be patient and responsible to avoid people's talk and fulfill the norms of the Moroccan society. Some respondents (25.5\%) selected 'oppressed' as a situation of divorced women. This can be attributed to the fact that after divorce, women suffer from psychological anxiety and societal pressure. They are oppressed by the social order that obliges them to remain in their expected role as wives and mothers. Since divorced women did not realize the expectations of society, they do not belong to the category of the somewhat liberated women.

Moreover, $15.5 \%$ of respondents believe that the best word that would describe divorced women is irresponsible. Those who think that divorced women are irresponsible may have the idea that women should be capable of handling all the household matters. Divorced women are accused of failing in assuming responsibility towards their husbands and children. The predominating idea that a woman is divorced because she is not responsible does not only reflect the backwardness of some mentalities but also hinder any change concerning divorced women.

Other respondents (14.9\%) opted for 'stigmatized' as a term that depicts the situation of divorced women. This can be attributed to the fact that divorced women are considered as a stigma in society. They are neither married nor single but a disgrace that tarnish the reputation of their families. $14,3 \%$ of respondents opted for 'vulnerable' to describe divorced women. This could be true since after divorce, women might feel emotionally weak and lonely. They usually do not receive any affection or support from their families or society in general. Also, jobless and divorced women face many obstacles in terms of money and integration that render them unconfident and fragile. In comparison with the above mentioned terms, few respondents selected 'unfaithful' and 'immoral' as adjectives that could describe a divorced woman. $6.8 \%$ of respondents opted for 'unfaithful' and 5.6\% chose 'immoral'. This can be explained by the fact that unfaithfulness and immorality are both stereotypes that Moroccans used to have about divorced women. Currently, these stereotypes seem to vanish and divorced women are not often considered to be immoral or unfaithful. The results also yielded that there are various suggestions proposed by the respondents. For instance, some suggested that she is a woman like any other women. Others described a divorced woman as a victim of an unhealthy relationship; that is to say, the husband is an abuser, an alcoholic or an irresponsible person. Also, some respondents claimed that she is the responsible of the break-up. The most repeated suggestions are: a woman who has gone through an unsuccessful experience of marriage and a strong woman who got liberated from a life that she did not live as she wants.

\section{Divorced women and the "third space" in fez}

Respondents are given two options to choose from, either they agree that divorced women occupy a third space and say 'yes' or they decline it and say 'no'. The results reveal that $41 \%$ of respondents claim that divorced women occupy a third space whereas 59\% claim the opposite. These statistics show that almost half of the respondents confirm that society put divorced women in a third space (they are neither equal to men nor to married women) as Figure 3 illustrates.

The situation of divorced women in Morocco is not very promising. Divorced women are looked down by society as whole; they do not fit in the paradigm that society sets out. They have been treated, intentionally or unintentionally, differently from the other "normal" women whom conduct go along with the social order. The divorced woman is intensively accused and blamed for deviating from the right path that is traced for her. This deviation is the reason behind the way she is looked at in society as a defect that needs to get rid of. The situation of a divorced woman in Morocco can be summed up through this quote by Guessous "the woman finds herself, without a husband, in an unaccepted situation in the viewpoint of society; she is single and no more virgin but with no husband." [2] (author translation).

The respondents are divided into two categories, some who said 'no' and others said 'yes'. It is noticeable that the ones who said 'no' to the third space are between 18 years old and 30 years old. That is to say, they are young people who do not belong to the old generation and thus their vision towards divorce and divorced women is different than the vision of old people. Fatima says "ehh no no I don't think so because they can take part in other in the work force they can ehh do whatever they like I I don't think they are hindered from doing something in society unless when we talk about ehh law sometimes poor women and ehh those ah uneducated women who who don't know how to for example how to file a law suit against their husbands and so on." These respondents have a kind of optimistic view regarding culture and society. This optimism can bring about change since the young generation has new ideas, new mindsets and create way of interpreting issues. Also, they seem to hold a hope that things are changing or might change in the future. Most of them claimed that divorced women are human beings like any other women in society. Besides this, some of the respondents stated that the decision to get divorce is a personal one, so it is no one's right to blame them for doing so. One of the respondents claims that

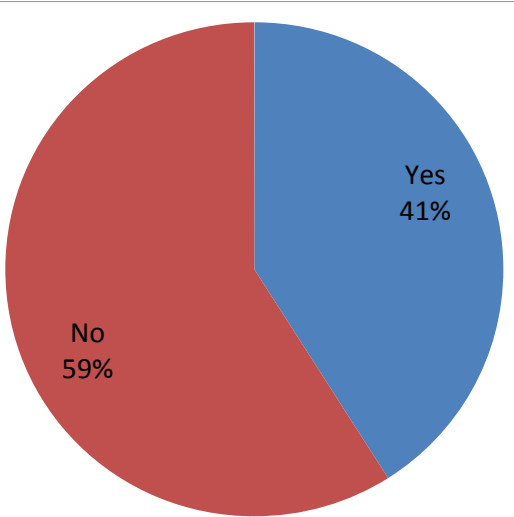

Figure 3: Divorced women occupy a "Third Space". 
"divorced women occupy a normal place in society exactly like men and women. Still, sometimes they are badly looked at." Another respondent writes "nowadays, they are equal thanks to the big number of right that family code provide to them." One of the most interesting responses that author received concerning this point is "I think we are equal but according to our society's stereotypes there are a lot of people that classify divorced women in the third category."

It is also noticeable that respondents who claimed that divorced women occupy a third space are above 40 years old. This can tell about the kind of background and ideas that these people have. However, young respondents - between 18-25 years old - are also with the idea that divorced women occupy a third space. Amal, an interviewee, strongly affirms this claim "yes, they are perceived as neither married women nor virgins so they are in-between." Most of the respondents write that the divorced woman is always accused of being responsible of that decision. One of the respondents asserts "basically, there is no equality between men and women in our society and therefore if we compare between divorced women and married or single ones, the privilege is given to the last ones."

Others believe that the core of the problem stems from the Moroccan society. These people blame society for being intolerant towards divorced women. Moreover, some respondents suppose that the patriarchal society and religion are the main factors behind the stigmatization of divorced women. Youness confirms this idea saying that "I think it has ehh a lot to do with the patriarchal society that thinks that every woman should have a husband and ehh in other words what we can say a tutor or someone to guard her because she is in danger if she doesn't have a husband." Divorced women are rejected by society, unless they are financially independent.

Paradoxically, almost all the people who said that divorced women do not occupy a third space, maintain that Moroccan society is unfair towards divorcees more than other women (single, married, widows). At this point, $69 \%$ of respondents confirm that Moroccan society is unfair towards divorced women while $31 \%$ of respondents did not confirm it as Figure 3 illustrates. Similar results were reached in a poll conducted by the World Public Opinion organization on 18 countries in 2008. "In Egypt, an overwhelming majority (80\%) thought that divorced women are mistreated (a great deal, 38\%; some, 42\%)". Since Egypt and Morocco share the same characteristics as both Muslim countries and part of the Arab world, the results match to a large extent.

\section{Conclusion}

The issue of divorced women and their sufferings in a patriarchal traditional society as the Moroccan one is almost a fact that people tend to take for granted. The study departed from this phenomenon that is experienced on a daily basis by some of the members of the society. It is hypothesized that divorced women are categorized in a third space which means that they are neither equal to ordinary women nor equal to men. To investigate closely this issue and try to understand the reasons behind this supposed biased attitude of Moroccans towards divorced women, a scientific and methodological data collection was conducted; the results were very interesting in the sense that they showed the extent to which Moroccan society is almost torn when it comes to thorny issues as the one under study. The population questioned is totally divided when it comes to the issue of the position divorced women occupy in the society.

Half of the population, 54\%, answered affirmatively when they were asked whether they believed that divorced women are not equal to married ones. Such outcome is revealing and can be provided as a clue to the understanding of the constraints that face divorced women in Moroccan society. A woman in Morocco, once divorced, finds herself ranked as second category and may continue her life enduring such harshness and cruelty that are usually felt in the conduct of Moroccans towards this category of women. Yet, when the same population was asked whether they believed that divorced women occupied a third space; that is to say, divorced women are neither equal to ordinary women nor equal to men; results appeared to be more interesting and revealing. Only $41 \%$ answered with 'yes' while 59\% said 'no'. Such a tiny difference, especially when it is seen in the light of the $54 \%$ aforementioned, tells us that extent to which the hypothesis of the study is challenging and needs further investigation.

The study revealed the conflicting oppositions which divide the Moroccan population when the issue of divorced women is raised. People disagree concerning this issue and this disagreement could not be explained in the present study. To reach a thorough understanding of the phenomenon many factors could have been taken into consideration such as the level of education and certain differences in the cultural background. First, a noticeable number of respondents showed reluctance towards the subject and yielded unwillingly and finally accepted the questionnaires. Others, however, refused to respond under different pretexts, the fact which could have influenced the result of this paper had these people fed this paper with their views. Second, many of the respondents did not respond returning the questionnaires excusing in one way or another.

Such are some of the limitations that faced the present study especially if we take a look at some interesting questions which divided the population questions. When they were asked whether all girls should get married, $48 \%$ of individuals said yes while $35 \%$ said no and only $15 \%$ who remained neutral. This difference tells much about the attitude of Moroccans towards the principal role a girl should be raised for. It is true that these different positions are not arbitrary but might be streaming from different ideological, cultural or biological (age and sex) platforms. It is clear that if these variables are included in a detailed way in the study, results could be more enlightening when the question of position of divorced women occupy in Moroccan society is raised.

The present paper does not possess any magical clues to overcome the aforementioned slipping limitations but departs from the fact that the question raised here taps on different aspects of Moroccan culture. Further investigations would deeply uncover the mystery which envelopes divorced women in Moroccan society and might bring about thorough understanding of the topic.

\section{References}

1. Badrane M (2014) Divorce au Maroc: 41000 cas en 2013, Today Morocco, May.

2. Blackstone AM (2003) Gender Roles and Society. Human Ecology: An Encyclopedia of Children, Families, Communities and Environments.

3. Katarzyna B (2013) Much, I am sure, depends on you: James Fordyce's Lessons on Female Happiness and Perfection. Studia Anglica Posnaniensia 48: 49-62.

4. Divorce [Def. 1], In Oxford Dictionaries Online.

5. El-Saadani SM (2006) Divorce in the Arab Region: Current Levels, Trends and Features. European Population Conference.

6. Gibson C (2009) Generation of Dissolving Gender Roles, May.

7. Lamrabet FZ (2008) Woman and the Reality of Divorce in Morocco, Civilized Dialogue, July. 
Citation: Soukayna A (2018) Gender Construction and Divorced Women in Morocco: Fez City as a Case Study. Arts Social Sci J 9: 409. doi: 10.4172/2151-6200.1000409

Page 8 of 8

8. Meredith P (1998) Hybridity in the Third Space: Rethinking Bi-cultural Politics in Aotearoa/New Zealand, Te Oru Rangahau: Maori Research and Development Conference, Massey University.

9. Naamane Guessous Soumaya, Beyond All Decency, Casablanca: Eddif, 1987.
10. Poll: Across the World Many See Discrimination against Widows and Divorced Women, June, 2003.

11. Schullo A (2015) Pink and Blue: Communicating Gender to Children, March.

12. Zimmerman DH (1987) West, Candace, Doing Gender, Gender \& Society, 125. 